\title{
LA SÁTIRA VI DE JUVENAL ("CONTRA LAS MUJERES») TRADUCIDA POR FRANCISCO DÍAZ CARMONA EN 1892
}

\author{
Ángeles García Calderón \\ Universidad de Córdoba
}

\section{Resumen}

La Sátira VI de Juvenal, titulada por el traductor "Contra las mujeres», es considerada como la composición más amplia y picante de su autor, destacando sobremanera el vigor de los rasgos, vivacidad de colores y perfección de estilo, mostrándose el poeta como un observador sagaz, un censor inflexible de las costumbres femeninas y un diestro pintor de ellas. El trabajo aborda, en su introducción, la influencia del autor latino en Francia, Inglaterra y España, poniendo de relieve en el primer caso la admiración de Boileau, que precedería a una amplia nómina de traductores en el siglo XIx, la mayoría de ellos en verso. Posteriormente se relacionan las traducciones en lengua española, desde la Declaración magistral sobre las Sátiras de Juvenal de Diego López en 1642 hasta las últimas de la primera década del siglo xxi. Una breve semblanza del traductor, Francisco Díaz Carmona, da paso al núcleo del trabajo: el estudio de la traducción de la Sátira VI, fundamentalmente de la métrica y estructuración, así como del análisis contrastivo, con especial incidencia en los errores morfosintácticos y léxico-semánticos.

Palabras Clave: Juvenal, poesía satírica, traducción, análisis contrastivo.

\author{
THE TRANSLATION OF JUVENAL'S SIXTH SATIRE \\ BY FRANCISCO DÍAZ CARMONA IN 1892
}

\section{Abstract}

Juvenal's Satire VI, entitled by the translator "Against women", is considered the broadest and most spicy composition of its author, highlighting the vigor of the features, vivacity of colors and perfection of style, showing the poet as a wise observer, a sharp censor of female customs and a skilled portrayer of them. The work addresses, in its introduction, the influence of the Latin author in France, England and Spain, highlighting in the first case the admiration of Boileau, which would forerun a wide range of translators in the 19 th century, most of them in verse. Subsequently, the translations in Spanish language are related, from Declaración magistral sobre las Sátiras de Juvenal by Diego López in 1642, to the last dating on the first decade of the 21st century. A brief sketch of the translator, Francisco Díaz Carmona, gives way to the core of the work: the study of the translation of Satire VI, mainly of metrics and structure, as well as of a contrastive analysis, with special emphasis on errors, both morpho-syntactic and lexical-semantic.

KEYwORDs: Juvenal, satirical poetry, translation, contrastive analysis. 


\section{INTRODUCCIÓN}

De todos los escritores que han compuesto poemas misóginos posiblemente ninguno haya superado al latino Juvenal en su Sátira VI, incluida en las dieciséis que redactara, debido a la severidad, ironía, gracejo y acidez que muestra el autor en ella. Compuesta por 661 versos, ya sería citada con frecuencia desde la Edad Media y es la fuente principal de los escritos misóginos que, a pesar del auge creciente de los estudios feministas, sigue gozando de una gran consideración entre los estudiosos del género satírico, pues junto a Ovidio, Virgilio y Horacio pocos autores de la literatura latina han ejercido una influencia tan sostenida en las letras europeas desde el Renacimiento. Juvenal contaba entre otros ilustres predecesores con Persio y Horacio, aunque, quizá por la certeza que tenía de la dificultad de superarlos, prefiriera imitar a otro antecesor más lejano, Lucilio, el inventor del género de las Saturae, según Horacio. En Lucilio se inspirará, asimismo, para tratar el tema de la condena de los vicios humanos, fustigando a una sociedad, la romana, que había ido degenerando las costumbres con el paso del tiempo ${ }^{1}$, aunque es preciso aclarar que Juvenal no escribe para dar soluciones morales, sino para poner de relieve que lo que plasma en sus versos es algo totalmente real. A este respecto, la virulencia de su lenguaje tiene razón de ser, no por la propagación de los vitia per se, sino por las consecuencias que estos acarrean. La fama de Juvenal no decrecería, más bien al contrario, siendo estudiado, imitado y traducido sobre todo en Francia, Espańa e Inglaterra.

En Francia, alguien tan intransigente en materia poética como Boileau no oculta su admiración por nuestro autor, expresada tanto en sus Satires como en su Art poétique. Veamos las dos citas:

Eh quoi! lorsqu'autrefois Horace, après Lucile, Exhalait en bons mots les vapeurs de sa bile, Et, vengeant la vertu par des traits éclatants, Allait ôter le masque aux vices de son temps; Ou bien quand Juvénal, de sa mordante plume Faisant couler des flots de fiel et d'amertume, Gourmandait en courroux tout le peuple latin, L'un ou l'autre fit-il une tragique fin? ${ }^{2}$

(Satire viI. "Sur le genre satirique")

Juvénal, élevé dans les cris de l'école, Poussa jusqu'à l'excès sa mordante hyperbole.

${ }^{1}$ De los cinco libros de sátiras de Juvenal, la vi, la más larga de todas, comprendería el segundo libro. Aunque las ediciones de Juvenal suelen titular cada sátira, aclaro algo obvio: los títulos de las sátiras fueron designados por los traductores de la obra y no por el propio Juvenal. El título de la vi es «Sátira contra las mujeres».

2 Para una mejor comprensión del texto, he modernizado las grafías francesas -oit en ait-. En esta y otras ocasiones en que cite poemas en otras lenguas, ofreceré la traducción española. Con el fin de que la visualización de la traducción sea mucho más fácil, y atendiendo al hecho de que en 
Ses ouvrages, tout pleins d'affreuses vérités,

Étincellent pourtant de sublimes beautés:

Soit que sur un écrit arrivé de Caprée

Il brise de Séjan la statue adorée;

Soit qu'il fasse au conseil courir les sénateurs,

D'un tyran soupçonneux pâles adulateurs;

Ou que, poussant à bout la luxure latine,

Aux portefaix de Rome il vende Messaline.

Ses écrits pleins de feu partout brillent aux yeux.

(Art poétique, II, vv. 157-167) ${ }^{3}$.

Tras el juicio de Boileau, varios serían los traductores franceses, la mayoría en verso, que se ocuparon de las Sátiras de Juvenal, de los que cito los más relevantes hasta 1869:

- Satires de Juvénal traduites par J. Dusaulx ${ }^{4}$. Paris: Imprimerie de M. Lambert, 1770.

- Satires de Juvénal et de Perse, traduites en vers français, avec des notes; par F. Duboys-Lamolignière. Paris: Ch. Pougens, 1801.

- Satires de Juvénal, traduites en vers français par Louis Vincent Raoul. Amiens: Imprimerie de Caron-Vitet, 1815.

ocasiones las notas incluyen el original latino y una o dos traducciones de él, he optado por la disposición versal:

Cuando en otro tiempo Horacio, tras Lucilio, con ingenio expulsaba el vapor de su bilis, $y$, la virtud vengando con rasgos refulgentes, le quitaba la máscara a los vicios de su época; o cuando Juvenal, con su incisiva pluma hacía fluir raudales de hiel y de amargura, con ira reprobaba a todo el pueblo latino, ¿tuvieron uno u otro acaso un fin trágico?

${ }^{3}$ Cuya traducción sería:

Juvenal entre gritos de la escuela educado, llevó hasta el exceso su hipérbole incisiva.

Sus obras, bien colmadas de espantosas verdades, destellan, sin embargo, sublimes hermosuras:

ya sea que carta llegada de Caprea

destroce de Sejano la estatua adorada, o bien que haga correr al Consejo a los senadores, de un suspicaz tirano pálidos aduladores; o que, llevando al límite la lujuria latina, a los zafios de Roma venda a Mesalina, en sus escritos brilla un fuego muy hermoso.

4 «Ancien Commissaire de la Gendarmerie, de l'Académie Royale des Sciences et Belles Lettres de Nancy». Obra que se reeditaría en las décadas siguientes, generalmente «revue, corrigée et augmentée», como, por ejemplo, la de 1803 por M. Villeterque (Paris: Imprimerie de Crapelet) o la de Jules Pierrot en 1825 (Paris: C.L.F. Panckoucke). 
- Satires de D.J. Juvénal, traduites en vers français, avec le texte en regard, et accompagnées de notes explicatives, par V. Fabre de Narbonne. Paris: Théophile Berquet, 1825.

- Satires de D.J. Juvénal, de Perse et de Sulpicia, Traduction nouvelle; par J.J. Courtaud-Divernéresse. Paris: Maire-Nyon Libraire, 1831.

- Satires de Juvénal et de Perse, traduites en vers français par M. Jules Lacroix. Paris: Firmin-Didot Frères, 1846.

- Les Satires de Juvénal traduites en vers français par J.H. Curé. Paris: E. LachaudDidier et $\mathrm{C}^{\mathrm{e}}$, 1869.

En Inglaterra el texto de Juvenal ha gozado siempre de gran éxito, y por lo que se refiere a la sátira en cuestión la controversia ha estribado más en la longitud del texto, ya que el latinista de Oxford Eric Otto Winstedt en 1899 descubrió en la Biblioteca Bodleiana de su ciudad un manuscrito del siglo XI o principios del siglo XII con 36 versos adicionales (34 colocados después del verso 366, y dos más después del 373). La realidad es que los versos no aportan nada original al texto traducido, siendo para este asunto interesante la opinión de uno de los editores españoles modernos más prestigiosos, Bartolomé Segura Ramos, que aclara, en su introducción a la edición de las Sátiras, la cuestión de los versos del manuscrito de Oxford:

Por mi parte, debo decir que el fragmento de Oxford 1-34 describe a unos señores afeminados que se introducen en casa de las seńoras para enseñarles a bailar, así como otras actividades más o menos inconfesables, y que luego acaban acostándose con dichas seńoras; el fragmento constituye en cierto modo un doblete de los versos siguientes, los dedicados a los eunucos con quienes a su vez las mujeres tienen asimismo relaciones sexuales; a mi juicio, dicho fragmento interrumpe la secuencia, alterándola y entorpeciéndola. Si es de Juvenal, está truncado: caso de haber estado completo, sin duda se hubiera podido insertar en algún otro punto, dado que, como hemos dicho más arriba, Juvenal procede en esta sátira por pequeñas secciones autónomas, con total independencia, en algunos casos, unas de otras (Segura 2001: LXV).

El escritor más influyente de la Restauración inglesa, John Dryden, traduciría en 1693 las Sátiras de Juvenal en verso, obra que ha sido continuamente reeditada desde entonces, a pesar de que Dryden, como en la mayor parte de sus traducciones, no fuera fiel en exceso al texto original, como ya pusiera en su momento de relieve el dramaturgo y traductor canario Antonio Saviñón 5 . A Dryden suele atribuirse la noción de que el traductor debía tratar de imaginar cómo habría escrito el autor si hubiera sido un compatriota contemporáneo, idea que expresa en su «Discourse Concerning the original and Progress of Satire»:

This must be said for our Translation, that if we give not the whole Sense of Juvenal, yet we give the most considerable Part of it: We give it, in General, so clearly,

5 Véase a este respecto García Garrosa \& Lafarga 2004: 46. 
that few Notes are sufficient to make us Intelligible: We make our Author at least appear in a Poetique Dress. We have actually made him more Sounding, and more Elegant, than he was before in English: And have endeavour'd to make him speak that kind of English, which he wou'd have spoken had he liv'd in England, and had Written to this Age (Dryden 1693: xxxix).

En lengua española, aparte de la Declaración magistral de Diego López en el siglo XVII ${ }^{6}$, la primera traducción de Juvenal se debe al eclesiástico, primer obispo nivariense y arzobispo de Granada Luis Folgueras y Sion. En las once páginas de que consta su prólogo, Folgueras explica cómo empezó su traducción «sin entender bien lo que era traducir», y las dificultades con que se iba encontrando:

El primer verso dice mas que el texto, el segundo menos, el tercero nada. Esta locucion no es pura; aqui se falta á la propiedad; alli gasta usted para un emistichio casi dos versos ¡Qué conciso el original, qué vigoroso, y que frio, y desleido en este pasage. Es otra imagen es hermosa, pero no está en el autor. Es serlo esto, y no interprete (p. III).

Disecciona luego su predilección por el verso, en contra de la prosa («el poeta traducido en prosa ya no es poeta, sino autor prosaico»), así como su fidelidad al texto:

Su original, debe, tal qual es presentarle sin añadir ni quitar, so pena de ser infiel, y de que, al autor si resucitara asistiera derecho de reconvenirle, y hacerle cargo hasta de las perfecciones suplantadas. Cada uno está contento con ser lo que es, y los autores mas que nadie. Hacerles decir lo que no dixeron, es mentir; y hacérselo decir sin la gracia y hermosura que ostentan, es por un término cruel deslucirlos y desfigurarlos. Y si tanto á un Poeta desazona y aflige no mas que el oir leer ó recitar sus versos, ¿quánto mas el verlos desnudos é indecentes, rotos, ó ridículamente ataviados en las manos de un traductor atrevido é ignorante? (pp. 4-5).

Finalmente, en una nota al prólogo, explica que, en aras de las buenas costumbres de su país, ha suprimido la Sátira IX y algunos pasajes de la Sátira VI y de otras. En general, Folgueras sigue muy de cerca la traducción francesa en prosa de 1770, de J. Dusaulx. Pero, a pesar de su defensa de la fidelidad al texto, y como es común entre lo que se defiende y lo que luego llevan a cabo los traductores, el resultado no confirma sus palabras, como podemos ver ya desde el inicio:

Credo Pudicitiam Saturno rege moratam

in terris uisamque diu, cum frigida paruas

praeberet spelunca domos ignemque laremque

et pecus et dominos communi clauderet umbra,

${ }^{6}$ El trabajo del humanista Diego López, que nació en Valencia de Alcántara (Extremadura) y durante muchos años se dedicó a la enseñanza de las lenguas clásicas en Toro, Mérida y Olmedo, y posiblemente en otras ciudades, parece ser que alcanzó gran importancia debido, sin duda, a que estaba escrita en castellano y era más asequible por el declive del estudio del latín. 
siluestrem montana torum cum sterneret uxor

frondibus et culmo uicinarumque ferarum

pellibus, haut similis tibi, Cynthia, nec tibi, cuius

turbauit nitidos extinctus passer ocellos,

sed potanda ferens infantibus ubera magnis

et saepe horridior glandem ructante marito. bos y heptasílabos

Diez primeros versos de Juvenal que Folgueras traduce por 19 endecasíla-

No me niego á creer que allá en los días

que Saturno reynaba,

Homestidad andaba

por el mundo, y mostróse largo tiempo

quando eran casas las umbrias cuevas

donde lares, y hogar, ganado y dueños

una sombra comun los abrigaba.

Silvestre cama la muger silvestre

de bálago y ramage componía,

y con pieles de fieras de al contorno.

No cierto parecida

á tí, ó Cinta, ni á la otra Lesbia

cuyos bellos ojuelos

las lágrimas turbaron, derramadas

en la muerte del caro paxarillo.

Los pechos enseñaba

con que robustos chicos sustentaba,

teniendo á veces mas deforme aspecto

que su marido de bellotas harto ${ }^{7}$.

Tras la traducción de Folgueras, y ya a finales del XIX, encontramos la de Díaz Carmona y Vigil, objeto de nuestro trabajo: Sátiras de Juvenal y Persio traducidas en verso castellano por D. Francisco Díaz Carmona y D. José M. Vigil, Madrid:

7 Alargamiento en exceso de los diez versos, que pueden traducirse en diez:

En los días de Saturno, creo que moró el recato en la Tierra, asentándose durante largo tiempo; cuando heladas cavernas eran hogar y lares del ganado y sus amos, en una común sombra; la rústica mujer extendía un tosco lecho con hojas, broza y pieles de fieras del mismo hábitat, diferente a ti, Cintia, como de ti, a quien la muerte de un gorrión enturbió tus ojuelos; e incluso a mamar daba a sus robustos hijos, más ruda que el marido que roía bellotas. 
Librería de la viuda de Hernando, 1892, que da paso a una serie de traducciones al español, que se recogen en las referencias bibliográficas finales ${ }^{8}$.

\section{EL TRADUCTOR DE JUVENAL EN EL VOLUMEN}

Francisco Díaz Carmona (1848-1913), nacido en Motril, se licencia en Filosofía y Letras en la Universidad de Granada, ejerciendo como auxiliar de Geografía e Historia en el Instituto de Enseńanza Media de Granada, y como catedrático por oposición de la misma disciplina en Gijón, Ciudad Real, Córdoba y Granada. En esta labor representa al grupo de catedráticos de instituto de la segunda mitad del siglo XIX que consolidaron la construcción de la Geografía y la Historia como disciplina escolar y la de catedrático como una profesión docente?. Cultivó, asimismo, la profesión de periodista, poeta, erudito historiador y autor de manuales, siendo colaborador de La Ciencia Cristiana, El Siglo Futuro y otros periódicos, en los que publicaría varios artículos sobre la novela naturalista. Sus principales obras son Estudio sobre la Atlántida (Madrid: Tip. Gutenberg, 1884), Compendio de Historia Universal (Córdoba, 1886), Historia Universal (Córdoba: Imp. del Diario, 1887), Elementos de Historia de España (Córdoba: Tip. La Verdad, 1896), Compendio de Historia de España (Córdoba: Tip. La Verdad, 1898), Historia de la Santa Iglesia Católica para uso de las familias (Friburgo de Brisgobia: B. Herder, Librero-Editor Pontificio, 1895). Poeta y traductor, versionaría La Atlántida de Mosén Jacinto Verdaguer (Madrid: Tip. Gutenberg, 1884) y las Sátiras de Juvenal (Madrid: Librería de la viuda de Hernando, 1892), traduciendo también la Historia de la Iglesia del cardenal J. Hergenroether (2 vols., Madrid, 1883, 1889) ${ }^{10}$.

${ }^{8}$ Menéndez Pelayo, en su Bibliografía hispano-latina clásica, cita una traducción de 1870, que no he podido consultar: Sátiras de Juvenal, traducidas del francés por Alfredo Álvarez.

${ }^{9}$ La información más completa sobre Díaz Carmona se encuentra en Peiró Martín y Pasamar Alzuria, 2002: 215.

${ }^{10}$ Como poeta Díaz Carmona escribía, a menudo, en endecasílabos con rima, como podemos ver en este soneto de su autoría, cuyo esquema rítmico (ABBA ABBA CDC DCD) es totalmente clásico, y que con frecuencia encontramos en la traducción de Juvenal.

LA FORTUNA

Jugadora de azar es la fortuna que con mil veleidades nos engańa: tira el dado primero, y vil cabaña nos da para nacer o regia cuna.

Vuele a tirar, y amable o importuna nos prodiga favores, o con saña gloria y riqueza, cual ligera cańa va tronchando al pasar una por una.

De sus caprichos víctimas vivimos; ora perdiendo lo que ayer ganamos, o recobrando ya lo que tuvimos. 


\section{ANÁLISIS DE LA TRADUCCIÓN DE LA SÁTIRA VI}

De los cinco libros de Sátiras de Juvenal el II incluye únicamente la Sátira VI, la composición más famosa y extensa de Juvenal: 661 versos. La sátira va dirigida a un hipotético amigo del autor, Póstumo, a quien trata de disuadir para que no se case, pues la castidad ha desaparecido (1-37). Pero, conforme avanza el poema, el receptor inicial se deja de lado y la diatriba se convierte en un conjunto de retratos de mujeres con sus singularidades y caprichos, y que Juvenal describe por medio de imágenes que van desde lo irónico a lo cruel y repugnante. La extensión de la diatriba se inicia con un grupo reducido de mujeres, pertenecientes a la clase alta romana; posteriormente, la sátira ya no es solo un ataque furibundo contra las mujeres y sus vicios, sino también una crítica contra la institución del matrimonio. La misoginia e indignación del poeta se vuelven más evidentes en otro motivo recurrente del poema: las mujeres ya no están subordinadas a sus maridos, sino que por el contrario muchos de ellos han ido asumiendo el papel femenino.

La traducción de la Sátira VI de Juvenal está incluida en el siguiente volumen: Sátiras de Juvenal y Persio traducidas en verso castellano por D. Francisco Díaz Carmona y D. José M. Vigil. Madrid: Librería de la viuda de Hernando y C. ${ }^{a}$ («Biblioteca Clásica tomo CLVIII»), 1892. Lo que en un primer momento, dada la coautoría del volumen, puede entenderse o deducirse como una obra en colaboración, una vez consultado el libro no resulta tal ya que las Sátiras de Juvenal están traducidas por D. Francisco Díaz Carmona y las de Persio por D. José M. Vigil; así, de las 440 páginas de que consta el libro las correspondientes a Díaz Carmona son 314, distribuidas de la siguiente manera: «Introducción a Juvenal» (pp. viI-L); «Vida de Juvenal» (pp. LI-LIII); «Sátiras de Juvenal» (pp. 1-254). La Sátira VI lleva por título "Las mujeres», y comprende desde la página 77 hasta la 119. Antes de iniciar su traducción Díaz Carmona explica el argumento, que por su interés transcribo:

Esta es, sin duda, la composición más vasta y picante de Juvenal, donde el vigor de los rasgos, la vivacidad de los colores, la magistral perfección del estilo, las bellezas de primer orden abundan más que en ninguna otra de las suyas. Nótase, sin embargo, en el plan de ella falta de arte, pues se reduce à una serie de retratos de mujeres viciosas, que se suceden sin transición ni método; pero este defecto se halla tan admirablemente compensado con las bellezas de todo género que en la sátira abundan, que siempre quedara ésta corno la obra maestra de Juvenal, el cual se muestra en ella observador sagaz, pintor habilísimo, censor justo é inflexible de las costumbres. Otro defecto aun más grave afea esta sátira, ó sean los cuadros en que se pinta al desnudo y con tal lujo de pormenores y crudeza de expresión, que no pueden trasladarse à ninguna lengua los vicios y torpezas de las damas romanas. Sean cuales fueren las razones que puedan atenuar tal violación de la moral en los

Y en este afán perpetuo en que giramos ¡ay! tan sólo la vida que perdimos es la que nunca a recobrar llegamos. 
escritos de un poeta pagano, y sin olvidar que su propósito era hacer aborrecibles los vicios que con tanta viveza describe, he creído de mi deber suprimir ó modificar, tanto en ésta corno en las demás sátiras, aquellos pasajes que no puedan trasladarse sin ofensa del decoro (Díaz Carmona 1892: 77).

El análisis que llevaré a cabo se basa en una lectura atenta de la traducción española, que incluye todo aquello que he creído digno de resaltar. No he partido de un esquema prefijado ni establecido de antemano, sino que he realizado varias lecturas minuciosas de la traducción, todas ellas con una actitud crítica en cuanto al lenguaje se refiere, tratando de poner de relieve las sutiles diferencias existentes entre el original y la traducción. Centrándonos en el relato, y en concreto en el buen o mal uso de la lengua en la traducción, y sin que estas observaciones supongan una exhaustiva revisión, procede distinguir algunas objeciones que dividiremos en tres apartados, según se refieran a la métrica, así como a todo tipo de errores morfosintácticos y errores léxico-semánticos. De este modo, podremos sacar conclusiones que nos permitan afirmar el tipo de traducción que ha llevado a cabo el traductor, aunque ya este, en la explicación del argumento de la sátira, explicite al lector que ha «suprimido y modificado los pasajes que ofenden al decoro».

\subsection{MÉtrica}

De modo general se puede afirmar que la traducción, en lo que respecta a la métrica, no tiene ningún esquema predeterminado, como veremos a continuación al analizar los versos, las estrofas y el poema.

\subsubsection{El verso}

El traductor, buen versificador sin duda, utiliza dos tipos de versos en su trabajo: el endecasílabo y el heptasílabo, los dos con rimas consonantes. Mucho más abundante el primero, ello no es óbice para que en algunas estrofas la correlación sea prácticamente similar, como en el caso que cito a continuación ${ }^{11}$ :

$\begin{array}{ll}\text { Así, mientras florece } & 7 \mathrm{a} \\ \text { Con hermosura juvenil, domina; } & 11 \mathrm{~B} \\ \text { La oveja canusina } & 7 \mathrm{~b} \\ \text { Pide al esposo, y viñas en Falerno. } & 11 \mathrm{C} \\ \text { ¿Al ruego él cede tierno, } & 7 \mathrm{c}\end{array}$

${ }^{11}$ Dado que voy a citar profusamente la traducción, mencionaré únicamente la página o páginas.

12 "Oveja canusina», en referencia a Canusio, ciudad de Apulia situada en la orilla derecha del Aufido. 
Y piensa que se aplaca? Su afán crece,

Y todo esclavo que halla en su camino,

Cuantos tiene el vecino,

Los ergástulos todos apetece. (87)
$11 \mathrm{~A}$

$11 \mathrm{D}$

$7 \mathrm{~d}$

$11 \mathrm{~A}$

Este primer ejemplo ya nos sirve para entrever que el traductor opera de un modo totalmente libre, sin que sus versos se ajusten a norma o regla alguna, sino tal y como van surgiendo del examen del texto original latino ${ }^{13}$. No obstante, el verso más abundante es el de 11.

En dos o tres ocasiones encontramos "versos partidos», distribuidos tipográficamente en dos secuencias de $4+11$ u $11+4$, y que responden a una cierta lógica: bien a una objeción que se le hace al destinatario de la sátira (Póstumo), a la que luego contesta el propio poeta, bien a un diálogo ficticio entre la mujer y el marido a propósito de un esclavo; veamos los dos ejemplos:

-Más ¿̇ni una sola habrá que te contente

Entre tantas?

$$
\text { -Sea rica, continente, (88) }
$$

- «iCrucifica a este siervo!

-«¿Por qué crimen?

¿Lo merece? ¿Hay testigos? ¿Quién delata?...» (92)

Todos los versos en la traducción comienzan por mayúscula, costumbre antigua que se ha hecho regla, pero que no tiene sentido. El origen se encuentra en que los poetas clásicos usaban este recurso denominado esticomitia: concentrar en un solo verso un pensamiento completo. En la poesía moderna es un procedimiento en desuso, optándose por la lógica de utilizar la mayúscula a principios de verso únicamente cuando el verso anterior termina en punto.

De modo general el traductor traduce con versos de muy buen ritmo, viniendo marcado este a veces por el uso de las enumeraciones, o de palabras similares en sílabas; veamos algunos ejemplos:

¿Habrá del circo entre las gradas una

Á la que puedas entregar tranquilo

Tu cariño, tu honor y tu fortuna? (82)

Hipia todo lo olvida: esposo, hermana, Hogar, patria... (83)

${ }_{13}$ Así como en el caso de la traducción de Folgueras Sion se encuentran múltiples similitudes con la del francés J. Dusaulx, continuamente reeditada desde 1770, y que debió ser muy conocida en nuestro país, Díaz Carmona no parece tener un modelo predeterminado al que seguir o ajustarse, sino que, como afirma en su prólogo, su traducción es muy libre, y por tanto personal. 
¡Gran honor, si las ropas de tu esposa

Sacáranse á subasta! ¡Fueran cosa

De ver! Manoplas, cíngulos, cimeras (94)

En ocasiones el traductor «fuerza» los versos para conseguir 11 sílabas: «Todo ya la mujer se lo permite» (105), cuando lo normal habría sido: «La mujer se lo permite ya todo"; o incluso: "A la mujer se le permite todo».

Con frecuencia, las ideas expresadas en la traducción, que suelen finalizar con un punto, se cierran con un verso contundente:

¿Y es esto todo? Hay más: el inocente

Busca mujer honesta, hecha á la antigua.

¡Oh médicos! ¡Sangradlo! Está demente. (81)

A riesgo tal, y trémula vacila,

Queda pálida, inerte,

Y se le hiela el corazón de susto,

Pues ella sólo para el vicio es fuerte. (84)

En cuanto a las aliteraciones, suelen estar bien distribuidas en el verso:

A favor de la noche el infamante (85)

Asáltale el deseo

De rica copa de cristal, ó pide

Luego murrino ${ }^{14}$ vaso y el famoso

Diamante luego, que hizo más precioso

De Berenice el dedo. Diélo un día (87-88)

Como sucede en todas las traducciones en verso los grandes aciertos alternan, no con grandes errores en este caso, sino con versos muy mejorables, respetando el endecasílabo; cito algunos, con otra(s) sugerencias alternativas:

En tanto, de tu honor con menosprecio,

Ella se entrega al siervo ó al patricio. (95)

(En tanto, tu honor menospreciando,

ella se entrega al siervo ó al patricio).

Pues por cualquiera precio te adivina (111) (pues por módico precio te adivina).

${ }_{14}$ Los vasos murrinos eran muy raros y caros. Pompeyo los llevó a Roma por primera vez, y estaban hechos de mirra y arcilla, según otros eran de porcelana o de concha. Plinio el Viejo habla de ellos en su Naturalis historia, libro Xxxviı, dedicado a mineralogía, cristal de roca, ámbar, gemas, diamantes, piedras semipreciosas, etc. 


\subsubsection{La estrofa}

El traductor no sigue el principio de que las estrofas en general comprendan de cuatro a catorce versos, ni tampoco el que la primera estrofa marque el ritmo del resto. La lectura minuciosa de la traducción muestra que Díaz Carmona no se ajusta a un tipo fijo de estrofa, ni de rima, sino que responde a los versos que va generando la propia traducción, adaptando el sentido al texto original. De este modo, las estrofas pueden ser de 4, 6, 8 versos o más, dependiendo de la idea que le transmita el texto latino y que él va traduciendo sin un estudio previo de los 661 versos, bien suprimiendo o añadiendo versos y estrofas completas, respondiendo al principio que ya había indicado en la introducción de su traducción: «Aquellos pasajes que no puedan trasladarse sin ofensa del decoro» (77). En efecto, siguiendo esta premisa, Díaz Carmona suprime casi 15 versos (del 366 al 380), ya que tratan de las prácticas sexuales, que el traductor debió considerar impúdicas:

Sunt quas ennuchi imbelles, ac mollia semper oscula delectent, et desperatio barba, et quod abortivo non est opus. Illa voluptas summa tamen, quod iam calida matura iuventa inguina traduntur medicis, iam pectine nigro. Ergo expectatos, ac iussos crescere primum testiculos, postquam coperunt esse bilibres, tonsoris damno tantum rapit Heliodorus. Conspicuus longe, cunctisque notabilis intrat balnea, nec dubie custodem vitis et horti provocat, a domina factus spado. Dormiat ille cum domina: sed tu iam durum, Postume, iamque tontendum ennucho Bromium committere noli. Si gaudet cantu, nullius fibula durat vocem vendentis pratoribus ${ }^{15}$. Organa Semper (Juvenal vv: 366-380)

sería esta:

${ }^{15}$ Cuya traducción, para que el lector de este trabajo pueda entender mejor la supresión,

Las hay que se embelesan con los mansos eunucos: sus besos no te pinchan por la falta de barba, ni hacen falta abortivos. Pero el placer es máximo, los llevan a los médicos en pleno desarrollo, con los huevos ya negros, pesando un par de libras. Entonces va Heliodoro y corta los testículos, que se esperó primero y ordenó que crecieran, todo ello en detrimento tan solo del barbero. Visible uno de lejos, entra ilustre entre todos en los baños y reta al guardián de vińa y huerto: es el que ha hecho su ama operar. Duerme con ella; pero tú, Póstumo, no confíes a este eunuco a tu Bromio, ya púber y en edad de pelarse. Si gusta el canto a los que su voz al pretor venden, no hay fíbula que dure. 
Una prueba evidente de que las estrofas no están determinadas por norma alguna es el hecho de que en ocasiones redacte su traducción en pareados:

¿Que el coturno calzando,

Y el límite y las reglas olvidando

A la sátira dados, con aliento

Propio del grande Sófocles, os cuento

Casas $(s i c)$ que nunca vieron las latinas

Comarcas, ni las rútulas colinas? ${ }^{316}$.

Dos figuras retóricas, o efectos poéticos, son empleadas profusamente en la traducción, el encabalgamiento y el hipérbaton; una tercera se encuentra en ocasiones: la anáfora. El encabalgamiento es continuo en toda la traducción, alargando o prolongando el verso al siguiente. El hipérbaton, o alteración del orden sintáctico habitual, también es constante, posibilitando así los versos endecasílabos. En ocasiones coinciden las dos figuras en los mismos versos, como en el ejemplo siguiente:

Y á la sierpe de plata la cabeza

Mover se ha visto... (110).

La anáfora no es tan abundante, pero no es difícil de localizar:

¿Á qué el gasto excesivo?

¿Á qué el dispendio inútil de la cena,

Y para el tardo vientre el digestivo?

¿Ấ qué la fuente de monedas llena. (91)

${ }^{16}$ Los seis versos traducidos corresponden a cuatro de Juvenal, en una proporción exacta (como veremos al analizar la estructura del poema) de tres versos traducidos por cada dos del original; son estos:

Fingimus hac altum satura sumente coturnum

scilicet, et finem egressi legemque priorum

grande Sophocleo carmen bacchamur hiatu,

montibus ignotum Rutulis caloque Latino? (Juvenal vv. 634-637).

Para que podamos apreciar la traducción tan libre de Díaz Carmona, que parece sacrificar la comprensión en aras del verso, rima y musicalidad, transcribo la traducción de Segura Ramos, y luego otra mía:

Por ventura me invento yo esto y mi sátira toma el alto coturno y sobrepasando los límites y leyes de mis predecesores creo un gran poema báquico a la medida de Sófocles, desconocido en los montes rótulos y bajo el cielo latino? (Segura 1996: 88)

¿Me invento acaso esto y dejo que mi sátira calce el alto coturno?

¿He excedido los límites legales de mis predecesores y estoy creando un canto báquico digno de Sófocles, desconocida por los montes rútulos y por el cielo latino? 
Ó en la Cíclada estuvo desterrado,

Ó de la estrecha Jérifo evadióse. (112)

Finalmente, en lo que respecta al estudio de la estrofa en la traducción de Díaz Carmona, es preciso constatar que, junto a estrofas muy bien resueltas, otras no aclaran del todo el sentido del texto original. Esto pone de relieve un escollo habitual en las traducciones de poesía, que obliga al traductor a optar por la claridad o por el metro; quiero decir que en muchos casos la densidad de pensamiento del poema original no posibilita la tarea del traductor, sino todo lo contrario: a veces es preferible verter la idea completa antes que intentar ajustarse a un metro único, más aún en una obra de calado filosófico como la Sátira VI de Juvenal. En estos casos, en aras de una perfecta comprensión del poema, a veces es preferible traducir como si se tratara de prosa, aunque para tratar de respetar en la medida de lo posible el pensamiento del autor traducido (tanto en el fondo como en la forma) debamos hacer una elección intermedia, es decir, la disposición versal del texto, aunque ello no implique ningún tipo de métrica. Es claro que Díaz Carmona opta por la métrica antes que por la claridad del texto por el lector, o quizá no lo hiciera de manera consciente pensando que su traducción sería comprensible, cuando la realidad es que algunos pasajes son difícilmente interpretables, siendo seguramente el motivo el respeto al decoro del traductor, que a pesar de aclarar con notas filológicas otros pasajes, pasa de puntillas en otros, como el que transcribo:

\author{
Atque utinam ritus veteres et publica saltem \\ his intacta malis agerentur sacra! Sed omnes \\ noverunt Mauri atque Indi, quae psaltria penem \\ maiorem quam sunt duo Casaris anti-Catones, \\ illuc, testiculi sibi conscius unde fugit mus, \\ intulerit, ubi velari pictura iubetur, \\ quacumque alterius sexus imitata figuram est. (Juvenal vv: 335-341)
}

Y que es traducido así:

¡Pluguiese al cielo que con mas decoro

Fuese tratado el venerable rito

Del culto antiguo! Mas el indio y moro

Conocen el delito

Del que en femíneo traje disfrazado,

Penetró audaz en el lugar vedado

Al hombre, y do velada la pintura

Se ve, si copia varonil figura. $(98-99)^{17}$

indecoroso:

${ }_{17}$ Una traducción más exacta sería la siguiente, sin que ello implique que el traductor sea

¡Quiera Dios que el culto, y los ritos antiguos

pudieran celebrarse sin estas perversiones! 
Sin notas aclaratorias es difícil llegar a interpretar el texto, en el que se evita cualquier alusión a los órganos sexuales masculinos, comparados por su importancia (tamaño) a los Anticatones de César, contra el pretor Marco Poncio Catón, que había sido elogiado en dos panegíricos de Cicerón y Bruto.

Así pues, y de modo general, la traducción sacrifica con frecuencia el sentido y la comprensión del texto original, en aras de conseguir versos y estrofas que finalicen con rimas persuasivas o convincentes.

\subsubsection{El poema (la traducción)}

Tras el análisis del verso y de la estrofa, la estructura u organización de la traducción de Díaz Carmona muestra claramente tres rasgos predominantes:

a) Por cada dos versos del texto original resultan tres traducidos; así, 661 de Juvenal son equivalentes a 997.

b) El traductor no respeta la longitud de las estrofas del poeta latino, sino que corta o alarga dependiendo de la idea personal que tenga del argumento desarrollado.

c) Para dotar a la traducción de más énfasis el traductor recurre con bastante frecuencia a las interrogaciones y exclamaciones.

\subsection{Análisis CONTRASTIVO}

Para la elaboración de este análisis, he creído necesario considerar el texto meta en su contexto histórico, pues tanto las políticas de traducción como las corrientes estilísticas difieren en ambas épocas, más en el caso que nos ocupa, dada la diferencia de siglos entre el original y la traducción.

\subsubsection{Problemas lingüisticos}

\subsubsection{Errores morfosintácticos}

a) Proliferación de leísmos, laísmos y loísmos. En el controvertido y debatido problema de los leísmos, laísmos y loísmos, que en el tiempo en que escribía nuestro traductor no era tal, la Real Academia Española, en su Gramática de la lengua castellana, al hablar de "los pronombres personales», (Parte I, Capítulo IV, Artículo II) determina:

\footnotetext{
Pero indios y moros saben qué citarista introdujo un pene mayor que los Anticatones, de César, de donde huye un ratón consciente de que es macho y donde, por mandato se cubren pinturas que simulen escenas de otro sexo.
} 
Pronombres personales son los que se ponen en lugar de nombre que significa persona, ó cosa que hace su oficio, como: yo, tú, él. [...] La tercera persona tiene dos significaciones, una directa, y otra recíproca. En la significación directa tiene estas variaciones: él, y le para el masculino: ella, le, y la para el femenino: ello, y lo para el neutro; y así decimos: él es: hablémosle: á ella le está bien, díganla lo que quieran: ello parece fácil, pero no lo es (Gramática 1771: 36-37).

En esta cuestión es reveladora la opinión del prestigioso lexicógrafo Ahumada Lara (1999: 93), quien constata y explica que

La Real Academia de la lengua no ha mostrado demasiadas reticencias hacia el leísmo o uso de le por lo en función de complemente directo. Es más, entre 1796 y 1872 , le fue el pronombre recomendado por la institución para el complemento directo masculino, con excepción del neutro lo. Sólo a partir de 1854 tolera la alternancia le / lo, es decir, reconoce el empleo etimológico de lo como complemento directo. Jaén, como el resto de Andalucía y Aragón, distingue con toda nitidez el empleo etimológico de los pronombres átonos lo, la y le.

La cita de Ahumada viene a colación por su origen andaluz (Higuera de Arjona, Jaén), igual que el traductor Díaz Carmona (Motril, Granada), siendo algo sabido que en lo relativo a la construcción de leísmos, laísmos y loísmos los andaluces no suelen errar al utilizarlos; de ahí la extrańeza de que en la traducción encontremos algunos dispersos:

Es ya su liviandad. ¿Por qué un dechado

De perfecciones à Cesonia llama

Su esposo? De un millón dueño le (lo) ha hecho.

¿Por qué a Sertorio su Bibula inflama?

¿Tu piensas que la ama?

Pues no; sólo su rostro le (lo) cautiva. (86)

Al navegante audaz la nieve impide,

Asáltale (lo) el deseo

De rica copa de cristal, ó pide. (87)

Pues ¿quién ignora el femenino ungüento,

Y el manto en tirio múrice teñido?

¿Quién no vió el palo por su mano herido,

Y cual le (lo) retan del escudo armadas, (93)

¿No es lícito al esposo un solecismo?

Todo ya (a) la mujer se lo (le) permite,

Nada ilícito juzga, si presenta

Collar de ricas perlas su garganta,

Y áureos zarcillos en su oreja ostenta, (105) 
Eunuco gigantesco al que venera,

El juvenil cortejo, le (la) precede,

Y la ronca cohorte

Y el tímpano plebeyo el paso cede. (109)

La mujer que se empeña

En trastornar el juicio del esposo

Y azotarle (lo) después con un zapato, (115)

b) Elipsis en los versos. El respeto a la medida del verso endecasílabo lleva en ocasiones al traductor a la elipsis de artículos determinados e indeterminados, de preposiciones y de verbos, como podemos ver en los ejemplos siguientes:

- Cuelga guirnaldas en tu puerta, amigo;

Tiende sobre el umbral (una) hiedra copiosa.- (81)

Cuando el muelle Batilo

Baila la leda pantomima, enciende

A Tuccia (un) fuego súbito, suspira

Apula, y aun Tymele inmóvil mira;

¡Tymele, la inocente, que allí! aprende

La primera lección!... $(82)^{18}$

El siguiente ejemplo, algo más extenso, da fe de la profusión de elipsis de verbos y artículos:

Mas ¿cuál (es) la juventud, cual (es) la hermosura

De (la) que Hipia se prendó? ¿qué la movía

A ser de (un) infame gladiador esposa?

Pues Sergiolo era (ya) viejo, carecía

De un brazo y aguardaba

${ }^{18}$ La dificultad, en este caso, para comprender el pasaje es grande, ya que el traductor opta por la rima (suspira/mira), antes que por trasladar el sentido de los versos de Juvenal, que en este caso precisan además de una explicación por algún nombre, a pie de página; veamos los versos de Juvenal y su traducción lógica:

Chironomon Ledam molli saltante Bathyllo,

Tuccia vesica non imperat, Appula gannit, sicut in amplexu. Subitum et miserabile longum

attendit Thymele? Thymele tunc rustica discit. (Juvenal vv. 63-66)

Cuando el blando Batilo baila y remeda a Leda, la vulva de Tucia arde, gime Apula y suspira

[cual repentino abrazo, largo y digno de queja].

Mira Timele atenta, aún ingenua aprende.

Batilo era un famoso pantomimo, natural de Alejandría, que llegó a Roma y fue liberto por Mecenas. Pilades y él crearon una nueva clase de baile. Juvenal lo cita como nombre genérico de bailarín. 
Próximo ya el retiro; era horrorosa

Su faz; (un) tumor ingente

Formado por el casco le llegaba

A mediar la nariz, y pestilente

(un) Humor de sus ojillos destilaba. $(84)^{19}$

El conocido pasaje de la impudicia de Mesalina es, asimismo, representativo de varias elipsis de artículos indeterminados:

Mas ¡á qué hablarte del hogar privado,

A qué pensar en Hipia? Considera

A los rivales de los dioses; oye

Lo que un Claudio sufrió. Cuando sentía

$\mathrm{Al}$ esposo dormir, un vil tugurio

A su tálamo augusto prefiriendo,

De (una) sobornada sierva en compañía,

Y su madeja de ébano cubriendo

Con (una) rubia cabellera,

A favor de la noche, en (un) infamante

Lugar entraba la imperial ramera

Allí con (un) falso nombre, el rostro oculto,

Se dirige á su impúdico hospedaje

Para manchar con oprobioso insulto,

¡Oh Británico ilustre! tu linaje.

Luego, el salario vergonzoso pide,

$\mathrm{Y}$ cansada del vicio, mas no harta,

La última en salir es, y al fin se aparta

Cuando ya á todas el rufián despide.

$\mathrm{Y}$ encendida la faz, ardiendo el pecho

19 Texto de Juvenal y mi traducción:

Qua tamen exarsit forma, qua capta iuventa

Hippia? Quid vidit, propter quod ludia dici

sustinuit? Nam Sergiolus iam radere guttur

coperat, et secto requiem sperare lacerto.

Preterea multa in facie deformia, sicut

attritus galea mediisque in naribus ingens

gibbus, et acre malum semper stillantis ocelli. (Juvenal vv. 103-109)

No obstante, ¿qué belleza a Epia enardeció?

¿Su juventud? ¿Qué vio para admitir el nombre

de gladiadora? Pues su Sergio ya se afeitaba,

tullido era de un brazo y esperaba el retiro.

Tenía, además, una cara deforme,

un bulto en la nariz, equimosis del casco,

y su ojo rezumando una agria secreción.

La aclaración de que el gladiador Sergio ya se afeitaba la explica el hecho de que una vez cumplidos los cuarenta, los gladiadores solían cortarse la barba. 
En adúltero fuego, Mesalina

Torna, llevando al profanado lecho

Conyugal, el olor de la sentina. $(85)^{20}$

Un último ejemplo, alusivo a elipsis de dos preposiciones en un mismo verso:

Nada podrás ya dar si ella se opone;

$\mathrm{Ni}$ vender ni comprar, si ella no asiente:

Mandará en tus afectos; al amigo

20 Texto de Juvenal y mi traducción:

Quid privata domus, quid fecerit Hippia, curas?

Respice rivales divorum, Claudius audi

qua tulerit. Dormire virum quum senserat uxor,

ausa Palatino tegetem praferre cubili,

sumere nocturnos meretrix augusta cucullos,

linquebat, comite ancilla non amplius una.

Sed, nigrum flavo crinem abscondente galero,

intravit calidum veteri centone lupanar,

et cellam vacuam atque suam: tunc nuda papillis

prostitit auratis, titulum mentita Lyciscae,

ostenditque tuum, generose Britannice, ventrem.

Excepit blanda intrantes, atque ara poposcit.

[continueque iacens multorum absorbuit ictus.]

Mox lenone suas iam dimittente puellas,

tristis abit, et quod potuit tamen ultima cellam

clausit, adhuc ardens rigidae tentigine volue,

et lassata viris, sed non satiata recessit.

Obscurisque genis turpis fumoque lucerne

freda lupanaris tulit ad pulvinar odorem. (Juvenal vv. 114-132)

Mas ¿en saber te ocupas de qué hizo Epia en su casa?

Ve a rivales de Dios, de Claudio oye las cuitas.

Desde que su mujer lo veía dormido,

prefería un camastro al lecho imperial;

la augusta meretriz, de noche y con capucha

descuidaba a su esposo, seguida de una esclava.

Su pelo negro envuelto en una peluca áurea,

entraba en un burdel fétido y harapiento,

a un cuarto vacío reservado para ella;

desnuda, pechos de oro, se apodaba Lycisca,

mostrando el vientre que te alojó, buen Británico.

Recibe tierna al que entra y reclama el salario.

[Tendida boca arriba traga pollas enteras.]

Y cuando el encargado despide a las chicas aunque triste, se apaña en salir siempre la última;

su cuarto, aún caliente, por su ardiente clítoris,

se retira cansada, de hombres, mas no saciada.

Las mejillas negruzcas del humo del candil,

y el olor del burdel lleva al lecho imperial. 
Viejo, a quien vió (en) tu puerta (de) adolescente,

Ella echará de casa... $(91)^{21}$

En alguna ocasión, se da un caso curioso de empleo de para, en lugar de por: «... Las puertas, adornadas / Para las nuevas nupcias, abandona» (p. 92), cuando el Diccionario de la Lengua Castellana explicita de modo muy claro la significación de por: «POR. prep. causal, ó final, que sirve para significar la razón, ó motivo, que se tiene para hacer alguna cosa. (p. 737)

\subsubsection{Errores léxico-semánticos}

En este apartado trato de tres tipos de «desviaciones» o variaciones en la traducción, que se encuentran en todos los textos, tanto en prosa como en verso: omisiones, adiciones y alteraciones. Asimismo, un sucinto comentario sobre el vocabulario y sus implicaciones en la traducción.

a) Ya hemos visto, al hablar de la estrofa, cómo el traductor suprime o elimina 15 versos, omisión que ya había anunciado al explicar el argumento de la Sátira: «He creído de mi deber suprimir ó modificar, tanto en ésta como en las demás sátiras, aquellos pasajes que no puedan trasladarse sin ofensa del decoro" (77).

Las alteraciones o cambios son algo específico en la traducción de Díaz Carmona, ya que su opción por el verso y la rima lo llevan a modificar el original en aras de la sonoridad y musicalidad. Así, en el citado pasaje de Mesalina, ya vimos que la traducción de D.C. era:

A favor de la noche, en (un) infamante

Lugar entraba la imperial ramera

Allí con (un) falso nombre, el rostro oculto,

Se dirige á su impúdico hospedaje

Para manchar con oprobioso insulto,

¡Oh Británico ilustre! tu linaje. (85)

${ }^{21}$ Texto de Juvenal y mi traducción:

Nil unquam invita donabis coniuge, vendes

hac obstante nibil, nibil, hac si nolet, emetur.

Hac dabit affectus; ille excludetur amicus

iam senior, cuius barbam tua ianua vidit. (Juvenal vv. 212-215)

Nunca podrás dar nada si tu esposa se opone,

ni vender ni comprar, si ella no está de acuerdo.

Mandará en tus afectos: echará a aquel amigo

ya viejo, al que la barba le salió en tu puerta. 
Suprimiendo el nombre de Lycisca, y cambiando el orden de los versos de Juvenal, que tradujimos del siguiente modo:

a augusta meretriz, de noche y con capucha descuidaba a su esposo, seguida de una esclava.

Su pelo negro envuelto en una peluca áurea, entraba en un burdel fétido y harapiento, a un cuarto vacío reservado para ella; desnuda, pechos de oro, se apodaba Lycisca, mostrando el vientre que te alojó, buen Británico.

Un solo pasaje más nos muestra la continua variación entre la traducción de D.C. y la que debería ser, citando primero el original, luego la traducción y finalmente la mía:

Tres ruga subeant, et se cutis arida laxet, fiant obscuri dentes, oculique minores: "Collige sarcinulas", dicet libertus, "et exi; iam gravis es nobis, ut sape emungeris. Exi ocius, et propera; sicco venit altera naso".

Que la expresión de la mirada viva $\mathrm{O}$ la tersura de la tez le falte, Quedando el cutis árido y marchito; Que pierda de sus dientes el esmalte: - «Sal! le dirá el liberto favorito.

Tu maleta dispón y vete presto,

Pues verte moquear nos es molesto, Y además otra viene

Con las narices secas á tu puesto». (87)

Cuando arrugas le salgan y su piel se marchite, los dientes se ennegrezcan y los ojos se sequen ${ }^{22}$, oirá esto de un liberto: "Coge tu fardo y vete. Ya aguantamos bastante que te suenes los mocos. Vete pronto, que llega otra que no moquea".

b) El vocabulario utilizado por el traductor es casi siempre muy culto, lo que prueba su enorme erudición; no obstante, el acierto de los términos es en ocasiones discutible, debido quizá a la elección por la medida del verso y la rima; señalo algunos:

${ }^{22}$ La alopecia, la falta de dientes, las arrugas y la ausencia de cejas son recurrentes en imágenes del tópico de la vetula o mujer vieja, que Quevedo imitará en sus sátiras misóginas. Aunque la imagen que transmite el verso es la de «achicarse», «empequeñecerse los ojos», el verbo secar transmite mejor la idea de vejez. 
-El verso 18: caulibus ac pomis, et aperto viveret horto. Es trasladado por "Cuando coles y pomas en abierto...» (80). Mejor habría sido traducir por frutos o manzanas, como ya prescribía la $1 .^{a}$ edición del Diccionario de la Lengua Castellana de la RAE: Poma. s. f. Lo mismo que Manzana. Tómase particularmente por una especie de manzana pequeńa y chata, de un color verdoso. Es muy suave al gusto. (p. 736).

-Los versos 393 a 395 de Juvenal:

Dic mihi nunc quaso, dic, antiquissime divum,

Respondes his Iane pater? Magna otia cali;

non est, ut video, non est quod agatur apud vos.

son vertidos así:

Dime, te ruego, oh Jano, tú que eres

El más antiguo de los dioses, dime:

¿La súplica oyes tú de estas mujeres?

Despacio el cielo está; y aun me imagino,

Que hay poco allí que hacer;...

El término despacio es absolutamente inadecuado, ya que el sentido de la frase es de falta de trabajo, ociosidad, y que el traductor interpreta por «poco a poco»»3.

-En el pasaje en que la mujer se llena de afeites, al modo de Popea, Díaz Carmona utiliza cuatro términos inapropiados para describir la acción de maquillarse: aliño, pasta, barniza, adoba (**105-106), cuando habrían sido más acertados vocablos como emplastos de pan, cremas, ungüentos, cataplasmas, etc.

\subsubsection{La traducción de elementos culturales}

a) Nombres propios. En lo concerniente a la traducción de nombres propios, y aunque no pueda considerarse como obra de referencia, me ha sido muy útil el libro de Sándor Hervey y Ian Higgins Thinking translation. A course in translation method: French to English (London/New York: Routledge, 1992). En su estudio, los autores concluyen que, en la traducción de nombres propios, deben tenerse en cuenta tres cuestiones: en primer lugar, si hay opciones existentes para la traducción de un nombre concreto; segundo, las implicaciones de decantarse por una opción determinada en términos de

${ }^{23}$ Una traducción más exacta sería:

Dime, te ruego, Jano, tú, el Dios más antiguo, ¿respondes a estas hembras? Cuán ocioso está el Cielo; por lo que veo no hay nada en que os ocupéis. 
coherencia; y tercero, las implicaciones de una elección entre el exotismo, la transliteración y el trasplante cultural (Hervey y Higgins, 1992: 30). Pero en la traducción de D.C., por la cual pululan multitud de nombres propios de la mitología, de dioses y emperadores, de militares, patricios, abogados, bailarines, gladiadores y otros personajes de la sociedad romana, la opción más lógica es la transcripción del nombre tal como nos ha sido transmitido por la historia o la literatura, sin tener en cuenta otro tipo de consideraciones.

Dada la proliferación de nombres ya desde un primer momento en que se cita a Saturno para describir los tiempos denominados Edad de Oro, únicamente citaré los nombres en que el traductor traduce erróneamente o transcribe mal, indicando el nombre apropiado al lado, en cursiva:

Iberina (Hiberina), Tuccia (Tucia), Tymele (Timele), Antenoe (Autónoe), Eurialo (Eurialo), Hipia (Epia), Páris (Paris), Sergiolo (Sergio), Veiento (Veyentón), Cesonia (Cesenia), Bibula (Bíbula), Apolo (Peánn $\left.{ }^{24}\right)$, Niobe (Níobe), Emo (Hemo), Accilo (Asilo ${ }^{25}$ ), Laufela (Saufeia), Olgunia (Ogulnia), Hidímales (Hedímeles), Poppea (Popea), Jérifo (Serifos $\left.{ }^{26}\right)$, Petosyris (Petosiris), Alcesta $\left(\right.$ Alcestis $\left.^{27}\right)$.

Dos casos curiosos de gentilicios son reseñables en la traducción: Sérica y siculos. El primero aparece en los siguientes versos:

Hac eadem novit quid toto fiat in orbe, quid Seres, quid Thraces agant; secreta noverca. (Juvenal vv. 402-403)

Que D.C. traduce del siguiente modo:

Cuanto ocurre en el mundo ella lo sabe, Los asuntos de Sérica y de Tracia, (102)

Que debería ser, más exactamente:

Esas mujeres saben cuanto ocurre en el mundo, qué hacen seres y tracios...

El hecho es que, en Occidente, desde la Antigüedad hasta el Medievo, China fue conocida con varios nombres: Seres, Sina y Catay. El primero provenía

${ }^{24}$ Canto coral griego en honor de Apolo, con frecuencia de carácter guerrero (RAE).

${ }^{25}$ Nombre de un gladiador, posiblemente Marcus Atilius.

${ }^{26}$ Serifos, Serifo o Serifa es una de las 220 islas que componen el archipiélago de las Cícladas, cuyo nombre proviene de la palabra griega $\varkappa \dot{\varkappa} \lambda \iota_{\circ}$, (círculo), y hacía referencia a la singular distribución del archipiélago, que parecía extenderse como un círculo en torno a la sagrada isla de Delos.

${ }_{27}$ Alcestis, Alcestes o Alceste; en la tragedia de Eurípides, Alcestis, esta se ofrece a morir para salvar la vida de su marido Admeto. 
del término $S i$ (Ssu, seda en chino), nombre que fue transmitido por los griegos, modificado como SER. Ello implicaba que ya existía comercio de seda desde por lo menos finales del siglo in a.C. Así pues, con el término seres el traductor está aludiendo a los chinos.

El gentilicio sículos, incluido al final de la estrofa en que se azota a las criadas, en el verso latino siguiente:

Prafectura domus Sicula non mitior aula. (Juvenal, v. 486)

Que el traductor traslada del siguiente modo:

.... Oh mansión dura,

Más que la de los sículos tiranos! (107)

La traducción solo se justifica si pensamos que los sículos eran uno de los tres principales pueblos que habitaban Sicilia antes de la llegada de los colonizadores griegos, según la división étnica del historiador Tucídides (los élimos vivían en el lado occidental y los sicanos en el centro). Fueron los sículos quienes dieron nombre a la isla, siendo su núcleo de población más importante Siracusa, que más tarde sería la sede del poder romano en la Isla. Dado que los tiranos a los que se refiere, Fálaris y Dionisio I, no pertenecen los dos a Siracusa, sino que el primero era de Agrigento, son factibles (entre otras) dos posibles traducciones: a) Gobierno tan cruel como los de Sicilia; b) Gobierno tan tirano cual los siracusanos. Aclaro que, aunque Fálaris (o Falaris) era de Agrigento, los tiranos más famosos fueron los de la ciudad de Siracusa, siendo los más conocidos los comprendidos entre el 491 y el 212 a.C.

b) Alusiones culturales. Entre las numerosas alusiones a las culturas romanas Juvenal mezcla algunos referentes a otras naciones, como la siguiente sobre las costumbres judías:

observant ubi festa mero pede sabbata reges, et vetus indulget senibus clementia porcis. (Juvenal vv. 159-160)

Que Díaz Carmona traslada del siguiente modo:

En el país donde descalzo el rey El sábado celebra, y á los cerdos Permite envejecer antigua ley $(88)^{28}$

${ }^{28}$ Aludiendo a la ley de Moisés, que prohibía a los judíos comer carne de cerdo. Una traducción más exacta sería esta:

donde los reyes guardan el sabbat, pies desnudos, y la tradición deja a los cerdos morir viejos. 
Curioso es el pasaje que alude a los baños de Popea en leche de burras:

Interea freda aspectu ridendaque multo

pane tumet facies aut pinguia Poppaana

spirat et hinc miseri viscantur labra mariti.

ad meechum lota veniunt cute. Quando videri

vult formonsa domi? Moechis foliata parantur,

his emitur quidquid graciles huc mittitis Indi.

Tandem aperit vultum et tectoria prima reponit, incipit agnosci, atque illo lacte fovetur

propter quod secum comites educit asellas

exul Hyperboreum si dimittatur ad axem. (Juvenal vv. 460-467)

Que es traducido así:

Con ridículo alińo el rostro afea

Llenándolo de pasta, y exhalando

El craso ungüento que inventó Poppea,

Cuyo contacto manchará al esposo.

Mas ¿qué le importa a ella

Parecer en su casa limpia y bella?

Sólo para el amigo ella barniza

E1 semblante, y dispone

Nardo y perfumes de la India muelle.

Mas ya descubre el rostro; la postiza

Tez, volviendo A la propia, ya depone;

Ya empieza à conocérsela. Se baña

Luego en la leche, por lo cual doquiera

Una legión de burras la acompaña

Que, aun desterrada al hiperbóreo polo,

Allí por su mandato la siguiera. (105-106)

El Suplemento al Diccionario Histórico Enciclopédico de Bastús y Carrera explicita a la perfección la alusión a Popea y sus baños en leche de burra:

Poppea, esposa de Nerón, había inventado un cosmético particular que debía conservar la pastosidad y la delicadeza de la piel, y que se llamó poppeana de haberle ella inventado. Consistía en una pasta de miga de pan mojada en leche de burra, con la cual se cubría toda la cara antes de acostarse. Durante la noche esta pasta se secaba, de manera que por la mañana la cara de estas mugeres había de tener el aspecto de un embarrado de yeso lleno de grietas. Así es que Juvenal hablando detalladamente en su sátira $\sigma^{a}$ de esta pasta la llama tectorium. Á más se servían también de otra composición de arroz y de harina de habas para desarrugar la piel y ponerla lisa. Por la mañana después de haber levantado con esponjas esta costra que cubría la cara, se lavaban con leche de burra todavía caliente. Entre los antiguos la leche de burra servía no solo para restablecer el pulmón, sino también para dar frescura á la piel, acerca cuya propiedad había las opiniones más singulares. Plinio en el lib. xxvin de su Historia natural habla de la leche de burra como de un excelente cosmético, y con este motivo cita la superstición de algunas mugeres 
que se lavaban la cara con ella todos los días muchas veces. El mismo Autor en su libro xi y muchos otros escritores refieren que Poppea se hacía seguir en sus viages de una recua de quinientas burras para poderse bañaren su leche (Bastús y Carrera 1833: 41).

Digno de resaltar es el pasaje en que una dama, enfadada por su aspecto, hace azotar a los criados, mientras ella lee un «diario»:

Verberat atque obiter faciem linit, audit amicas

aut latum pictae vestis considerat aurum

et cadit, longi relegit transversa diurni

et cadit, donec lassis cadentibus "exi"

intonet horrendum iam cognitione peracta. (Juvenal: vv. 481-485)

Traducido como sigue:

Cruje el azote, y entretanto ella

Pinta su faz, recibe à sus amigas.

De un traje el oro y el dibujo vario

Mira; sigue el azote, y de un diario

Las noticias recorre; y sigue, sigue

Cayendo el duro azote hasta que el brazo

Cansado del verdugo se fatigue.

-«iSal»- grita fiera, cuando ya las manos

Dejaron de azotar... (107)

A la traducción de «diario» Díaz Carmona ańade la siguiente nota a pie de página:

En Roma no se conoció el periodismo propiamente dicho, pero se solían poner en los sitios públicos las noticias de los sucesos importantes para que llegaran à conocimiento de todos. Esto dio origen á, una especie de diarios (acta diurna), cuyas copias se difundían por todas partes, y en las que se daba cuenta, no sólo de los asuntos tratados en la curia, sino también de cuanto ocurría en la ciudad. (107)

Pero en realidad se trata, no de un diario (acta diurna), sino de una especie de libro de cuentas casero en el que se apuntaban los gastos cotidianos, por lo que sería más exacta una traducción como esta:

Y mientras esto ocurre, se maquilla y departe con amigas, o mira de un vestido el dorado; siguen los golpes, y ella revisa el gasto diario, hasta ver al cansado verdugo, y grita: "fuera", quedando satisfecha por impartir justicia.

c) Frases proverbiales. Muchos de los versos de las Sátiras de Juvenal han pasado a la posteridad como frases proverbiales, de las que puede ser ejemplo la conocida y archicitada cita mens sana in corpore sano, que es la segunda parte 
del verso 356 de la Sátira X: orandum est ut sit mens sana in corpore sano, que como el lector sabe no significa otra cosa que mente sana en un cuerpo sano. En este caso, es precisa la aclaración de que el sentido actual de la frase no es el mismo que en la época de Juvenal, que era el de tener un espíritu equilibrado en un cuerpo equilibrado, para así poder bien llevar a cabo la plegaria a los dioses; es decir, a pedirles lo que realmente nos conviene, en vez de rogar por cosas vanas y pasajeras que podrían perjudicarnos.

En la Sátira estudiada, también hallamos frases proverbiales que han pasado a nuestros días, y otras que pueden ser tenidas por tales. Entre los versos 141 y 143 encontramos dos posibles frases proverbiales, muy distintas en sus significaciones y separadas por un punto y aparte:

... vidua est, locuples quæ nupsit avaro.

Cur desiderio Bibulae Sertorius ardet?

$\mathrm{Si}$ verum excutias, facies non uxor amatur.

Traducidos así:

La rica que se casa con avaro

Es tan dueña de si cual la viuda.

¿Por qué a Sertorio su Bibula inflama?

¿Tu piensas que la ama?

Pues no; sólo su rostro le cautiva. $(86)^{29}$.

Expresada en verso, la primera sería:

La rica que se casa con avaro, tan dueña es de su vida

cual si fuera una viuda.

La segunda sería:

Ve al fondo de las cosas,

la realidad no evites.

En los versos 210 y 211 se resume todo el argumento de la Sátira:

... Igitur longe minus utilis illi

uxor, quisquis erit bonus optandusque maritus.

${ }^{29}$ En mi traducción:

... es cual viuda la rica que ata a un ruin.

¿Por qué arde Sertorio de lujuria por Bíbula?

Ve al fondo de las cosas: ama el rostro, no a ella. 
... Así, no creas

Que aunque el mejor de los maridos seas,

Menos gravoso te será el casarte. $(91)^{30}$

Pero sin duda las dos frases proverbiales más conocidas de la Sátira VI son las dos siguientes:

Audio quid veteres olim moneatis amici:

"Pone seram, cohibe." Sed quis custodiet ipsos

Custodes? Cauta est, et ab illis incipit uxor. (Juvenal vv. 346-348)

Traducida por Díaz Carmona así:

... Amigos, ya os escucho

Decir: «Cerrojos pon, la entrada veda.»-

Mas ¿quién guarda al guardián? Diestra es la esposa,

Y sobornando á aquél hará que ceda. $(99)^{31}$

Y, sobre todo, la alusión a la impudicia de Mesalina:

et lassata viris, sed non satiata recessit. (Juvenal v. 130),

traducida por:

Y cansada del vicio, más no harta, (85)

que vertida con más exactitud sería:

y se retiró cansada de los hombres, pero no saciada.

Frase que no ha perdido vigencia y que sigue repitiéndose continuamente en nuestros días.

${ }^{30}$ Más exactamente:

...así, menos fruto obtendrá

de su esposa el marido cuanto más bueno sea.

${ }^{31} \mathrm{O}$ mejor:

Oigoos, viejos amigos, decidme hace ya tiempo:

"Ponle un cerrojo, enciérrala." Mas ¿quién vigilará

al guardián? Es sagaz, y empezará por ellos. 


\section{CONCLUSIÓN}

A pesar del auge de los estudios de traducción en Espańa desde 1990, y de que multitud de trabajos se han ocupado de sintetizar la bondad de estos estudios ${ }^{32}$, algunos de los primeros supusieron un punto de inflexión y, asombrosamente, aún siguen teniendo vigencia; entre estos, el Essay on the Principles of Translation (1791), del profesor escocés Alexander Fraser Tytler. En el caso de este trabajo, dado que se trata de un estudio comparativo, aunque también prescriptivo, no parece ilógico juzgarlo según los principios enunciados por Tytler:

I. That the Translation should give a complete transcription of the ideas of the original work.

II. That the style and manner of writing should be of the same character with that of the original.

III. That the Translation should have all the ease of original composition (Tytler 1907: 9) ${ }^{33}$.

Como bien afirmara en 1996 un experto en traducción literaria: «Tytler se vale de estas tres leyes, que comprenden una serie de preceptos subordinados, para efectuar a lo largo de todo el Ensayo un análisis de un buen número de traducciones» (Pegenaute 1996: 25).

Respecto de la primera ley, es claro que el trabajo de Díaz Carmona transcribe las ideas de Juvenal fielmente, aunque la comprensión en algunos párrafos sea difícil para el lector. La segunda ley es evidente que no se cumple, ya que el estilo y forma de escribir de Juvenal y de Díaz Carmona son distintos, deudores cada uno de su época (sobre todo el poeta de Aquino) ${ }^{34}$. En cuanto a la tercera norma, y teniendo en cuenta el estilo de cada uno, en la traducción de Díaz Carmona se percibe transparencia y naturalidad.

De todas las traducciones al español publicadas hasta la de Díaz Carmona, posiblemente ninguna reuniera los méritos que esta atesoraba, debido en gran parte a la buena formación humanística del traductor, así como a sus dotes como poeta.

32 Una buena perspectiva sobre los métodos y los problemas de traducción en la historia de la traducción se halla en el trabajo de Aldridge 1961.

${ }^{33}$ Es decir: la traducción tiene que ofrecer una transcripción completa de la idea de la obra original; el estilo y la forma deben ser equivalentes a los del original; la traducción ha de poseer la naturalidad de la composición original.

${ }^{34}$ Lo que ya afirma Díaz Carmona en su introducción: «Las sátiras de Juvenal no tienen todas el mismo carácter. Mientras en unas ataca sin miramiento y poseído de la más ardiente indignación los torpes vicios de la sociedad romana, en otras adopta un tono apacible y tranquilo corno de quien dogmatiza y enseńa. En efecto, en aquéllas todo es pasión, fuego, indignación; muestra allí el poeta sus grandes dotes de pintor y observador; y empuñando la espada de Lucilio, ataca al vicio y al crimen, à los criminales y á los viciosos, persiguiéndolos implacable hasta sus últimas guaridas» (p. Xxxiv). 
Su cultura y su erudición permiten al traductor añadir multitud de notas filológicas que ayudan en muchos casos a la comprensión del texto original.

Tras analizar la traducción, y a pesar de detectarse la gran libertad de su autor al trasladar al español, ello no implica que este pierda el rastro del original, si pensamos que la permisividad que se toma el traductor respecto de él no desluce para cualquier buen «degustador" de poesía la viveza y buen tono de una traducción que continuamente nos ofrece pasajes animados y divertidos (como inicialmente debió pretender el poeta latino), todos ellos de una gran expresividad, que revelan el "alma satírica» del traductor; alma que traslada, una y otra vez, a sus versos estrofas tan dinámicas y veraces como la de la descripción de la influencia de la suegra en el matrimonio, de un gracejo sin par:

Mientras tu suegra viva,

Nunca aguardes la paz; hábil maestra

De tu mujer, la enseñará á arruinarte:

Ella también la adiestra

Del adulterio en el infame arte.

El billete amoroso

Ella le dicta; ella soborna al guarda;

Ella protege, criminal tercera,

Á oculto amante que impaciente aguarda.

¿Piensas tal vez que la virtud austera

La enseñe? Siempre ha sido provechoso

Á estas torpes ancianas

Hijas tener más torpes y livianas. (93)

ReCibido: septiembre de 2019; ACEPtAdo: diciembre de 2019 


\section{REFERENCIAS BIBLIOGRÁFICAS}

Decimus Iunius Iuvenalis: Saturae, Liber II (Satura VI). https://la.wikisource.org/wiki/Saturae_ (Iuvenalis...II/Satura_VI.

\section{A) Traducciones de Juvenal al español}

Sátiras de Juvenal (1817), traducidas en verso por don Luis Folgueras Sion, Madrid: Imprenta de doña Catalina Piñuela.

Sátiras de Juvenal (1870), traducidas del francés por Alfredo Álvarez, Madrid: Imprenta de El Pueblo.

Sátiras de Juvenal y Persio (1892), traducidas en verso castellano por D. Francisco Díaz Carmona y D. José M. Vigil, Madrid: Librería de la viuda de Hernando.

Persio y Juvenal (1959): Sátiras completas, con los colambios de Persio, traducción, prólogo y notas de José Torrens Béjar, Barcelona: Iberia.

Juvenal (1973): Sátiras, traducción de A. Espina, Madrid: Editorial Mediterráneo.

Juvenal, Decio Junio (1984 [1974]): Sátiras, introducción, traducción y notas de Roberto Heredia Correa, México: Universidad Nacional Autónoma de México.

La sátira latina. Lucilio-Horacio-Persio-Juvenal (1991), edición de J. Guillén Cabañero, Madrid: Akal Ediciones.

Juvenal-Persio (1991): Sátiras, intr. gen. de M. Balasch y M. Dolç, intr. part., trad, y notas de M. Balasch, Madrid: Biblioteca Clásica Gredos.

Juvenal (1996): Sátiras. Traducción, estudio introductorio y notas de Bartolomé Segura Ramos, Madrid: CSIC.

Juvenal (2002): Sátiras, prólogo, traducción y notas de Salvador Villegas Guillén, Madrid: Ediciones clásicas.

Juvenal (2007): Sátiras, edición bilingüe de Rosario Cortés Tovar, Madrid: Cátedra.

Juvenal (2010): Sátiras, traducción de Francisco Socas Gavilán, Madrid: Alianza Editorial.

\section{B) Otras OBRas}

AldRIDge, Alfred Owen (1961): «Le problème de la traduction au XVIII ${ }^{\mathrm{e}}$ siècle et aujourd'hui», Revue belge de philologie et d'histoire 39-3: 747-758.

Ahumada Lara, Ignacio (1999): El habla popular de Jaén en la literatura, Jaén: Editorial Jabalcuz.

Bastús y Carrera, Joaquín (1833): Suplemento al Diccionario Histórico Enciclopédico, Barcelona: Herederos de D. Agustín Roca.

Cortés Tovar, Rosario (2009): «Décimo Junio Juvenal», en F. Lafarga \& L. Pegenaute (eds.), Diccionario histórico de la traducción en España, Madrid: Gredos, p. 637.

Dryden, John (1693): «A Discourse Concerning the original and Progress of Satire», in The Satires of Decimus Junius Juvenalis. Translated into English Verse by Mr. Dryden, and several others Eminent Hands, London: Jacob Tonson. 
García Garrosa, M. Jesús y Francisco Lafarga (2004): El discurso de la traducción en la España del siglo XVIII, Kassel: Edition Reichenberger.

Herver, Sándor e Ian Higgins (1992): Thinking translation. A course in translation method: French to English, London/New York: Routledge.

López, Diego (1642): Declaración magistral sobre las Sátiras de Iuuenal, Principe de los Poetas Satiricos, Madrid: Diego Díaz de la Carrera.

Menéndez Pelayo, Marcelino (1952): Bibliografía hispano-latina clásica. Hostio-Plauto, edición preparada por Enrique Sánchez Reyes, Madrid: CSIC.

Pegenaute Rodríguez, Luis (1996): «Alexander Fraser Tytler y su Ensayo sobre los principios de traducción: la corriente normativo-prescriptiva en traductología», Hieronymus Complutensis 3: 23-33.

Peiró Martín, Ignacio e Ignacio Pasamar Alzuria (2002): Diccionario Akal de Historiadores españoles contemporáneos, Madrid: Ediciones Akal, S.A.

RAE (1771): Gramática de la lengua castellana, Madrid: Joachin de Ibarra.

RAE (1780): Diccionario de la Lengua Castellana, 1. edición, Madrid: Joaquín Ibarra.

Torre Villar, Ernesto de la (1975): "José María Vigil», en Semblanzas de Académicos. (Nuestros humanistas), México: Ediciones del Centenario de la Academia Mexicana.

Tytler, Alexander Fraser (1907 [1793]): Essay on the Principles of Translation, London: J.M. Dent \& co.; New York, E.P. Dutton \& co.

Vigil, José M. (trad.) (1879): Sátiras de Persio traducidas en verso castellano, México: Tipografía de Gonzalo A. Esteva. 